\title{
Impact of Gas Masks on Work of Breathing, Breathing Patterns, and Gas Exchange in Healthy Subjects
}

\author{
Stephane Bourassa RN MSc, Pierre-Alexandre Bouchard RT, and François Lellouche MD PhD
}

\begin{abstract}
BACKGROUND: The gas mask is used to protect military and non-military personnel exposed to respiratory hazards (chemical, biologic, radiologic, and nuclear agents). The objective was to evaluate the impact of the gas mask on indexes of respiratory effort and breathing patterns in a human model because no data exist. METHODS: The design of the study was a crossover evaluation with four 10-min conditions in a randomized order: with and without wearing the gas mask when at rest and when exerting a standardized effort. During the studied conditions, 14 healthy subjects were evaluated for breathing patterns, indexes of respiratory effort (work of breathing, pressure-time product for esophageal pressure, and esophageal pressure swing) and capillary blood gases. Continuous $\mathrm{S}_{\mathrm{pO}_{2}}$ was recorded during the tested conditions. RESULTS: The indexes of respiratory effort significantly increased when subjects wore the gas mask under the tested conditions (at rest and during effort). The work of breathing was significantly augmented with the mask (at rest, $0.40 \pm 0.32 \mathrm{~J} /$ cycle vs $0.25 \pm 0.10 \mathrm{~J} /$ cycle; effort, $5.96 \pm 3.32 \mathrm{~J} /$ cycle vs $4.43 \pm 2.50 \mathrm{~J} /$ cycle; $P<.001$ ). The other indexes of effort (esophageal pressure-time product and esophageal swing were all significantly increased, from 30 to $60 \%$, with a gas mask in comparison with at baseline without a gas mask). The impact on breathing patterns and $\mathbf{P}_{\mathrm{aCO}}$ was limited, without significant differences. Moderate hypoxemia was present during effort and was not increased by the gas mask. CONCLUSIONS: This study demonstrated a substantial increase in the indicies of respiratory effort both at rest and during exercise with a gas mask. Our measurements and findings may be referred in future research and development studies in this field. (ClinicalTrials.gov registration NCT02782936.) Key words: work of breathing; breathing pattern; respiratory effort index; chemical; biological; radiological; nuclear and explosive; gas mask; respiratory protective devices; gas exchange. [Respir Care 2018;63(11):1350-1359. @ 2018 Daedalus Enterprises]
\end{abstract}

\section{Introduction}

The gas mask is used to protect military and non-military personnel exposed to respiratory hazards. When only

\footnotetext{
Mr Bourassa, Mr Bouchard, and Dr Lellouche are affiliated with Centre de Recherche de l'Institut Universitaire de Cardiologie et de Pneumologie de Québec, Université Laval, Quebec City, Quebec, Canada.

Funding came from a sponsorship from a vocational program for injured Canadian military members released from the Canadian Armed Forces for medical reasons. In this case, funding was dedicated to a master's degree in experimental medicine. Funding sources played no role in the design of the study, the collection, analysis, the interpretation of data, the writing of the report, or in the decision to submit this article for publication.
}

Dr Lellouche is co-inventor of the $\mathrm{FreeO}_{2}$ system and co-founder of Oxynov. No support from this company was provided for the study. $\mathrm{Mr}$ Bourassa and Mr Bouchard have disclosed no conflicts of interest. considering U.S. military forces, $>1$ million people are potential users of these devices. ${ }^{1}$ The mask is a special interface that combines inspiratory and expiratory resistances, and that has an instrumental dead space, which possibly results in a rebreathing phenomenon. These different characteristics of gas masks may explain the sensation of respiratory stress or breathing difficulty experienced by the users of the masks at rest or during physical effort. ${ }^{2-5}$ A number of studies found in the literature eval-

\footnotetext{
Correspondence to François Lellouche MD PhD, Centre de Recherche de l'Institut Universitaire de Cardiologie et de Pneumologie de Québec, 2725, chemin Sainte-Foy, Ville de Québec, Québec, Canada G1V 4G5, E-mail: francois.lellouche@criucpq.ulaval.ca.
}

DOI: $10.4187 /$ respcare. 06027 
uated the impact of resistance on comfort ${ }^{6-9}$, and few studies evaluated the impact of gas masks on gas exchange. ${ }^{10}$ There are no data in the literature on the impact on work of breathing (WOB) and other indicies of effort in gas mask users. It is likely that the respiratory stress is related to increased WOB, which negatively affects the military personnel. Accurate evaluation of the impact on the WOB and understanding of the physiologic mechanism may improve the design for better-tolerated gas masks in the future.

The main evaluations of respiratory stress rely on the assessment of the comfort to breathe with a gas mask. Four studies included an assessment of the comfort in the function of breathing resistance while wearing a gas mask. $6,7,9,11$ These studies revealed that the comfort decreased proportionally with the increase of breathing resistance. ${ }^{6,7,9,11}$ Moreover, no study focused on comparing the comfort-breathing resistance relationship between at rest and during effort. Few data are available regarding the potential impact on rebreathing and the impact on oxygenation that results from the use of a gas mask. Arieli et al ${ }^{10}$ observed only a minor impact on gas exchange with gas masks when the subject was in a resting condition. Theses investigators did not repeat their study with the subject under physical effort.

To our knowledge, no study has ever assessed the indicies of respiratory efforts with an esophageal catheter as a conventionally recognized method in respiratory physiology. ${ }^{12-15}$ The aim of this study was to accurately measure the impact of the use of a gas mask on the indexes of respiratory effort, on breathing patterns and gas exchange in healthy subjects at rest and during standardized effort.

\section{Methods}

We conducted a randomized controlled cross-over study in healthy subjects to evaluate the physiologic impact of gas masks in subjects at rest and during effort (Fig. 1). The study was conducted at the research center of the Quebec Heart and Lung University Institute. The study was approved by the institutional ethics review board of the Quebec Heart and Lung University Institute. Written consent was obtained for all the subjects before their participation.

\section{Subjects}

The inclusion criteria were the following: no known significant cardiac and respiratory diseases, no history of epilepsy, no pathology that required chronic medication, no pregnancy, and correct face size in relation to the gas mask. The exclusion criteria were the following: declined to participate to the study, had claustrophobia, or had a history of esophageal pathology. Spirometry and usual demographic data like age, gender, weight, height, smoking habits, etc. recording were performed after inclusion.

\section{QUICK LOOK}

\section{Current knowledge}

The respiratory stress experienced by gas-mask users is well known but has never been accurately quantified. No study has evaluated the work of breathing or other index of effort with and without a gas mask at rest and during effort with adequate methodology. Few studies exist on the breathing comfort with masks; one study estimated the work of breathing by using a bench model.

\section{What this paper contributes to our knowledge}

In 14 healthy subjects, a population that represented the common users of the gas masks, we demonstrated a significant increase in all the indicies of effort (work of breathing, esophageal pressure time product, and esophageal swing pressure) when wearing a gas mask at rest and during a moderate effort (30-60\%). The impact on arterial blood gases and desaturation was small. Our data provided an accurate assessment of the impact of these devices on the healthy subject's respiratory physiology.

\section{Protocol}

The four 10-min testing conditions were in a split design: at-rest baseline (without and with the mask); and during effort (without and with the mask). During effort, the subjects walked on a treadmill (Nordic Track A2155, model 30234, Saint-Jerôme, Quebec, Canada) at 3 miles/h $(4.8 \mathrm{~km} / \mathrm{h})$ with an inclination of $10 \%$. The metabolic target generated for the effort was 7.4 metabolic equivalent of tasks, which represented a moderate intensity. ${ }^{16}$ At-rest conditions were conducted first, followed by effort conditions. Mask and no mask conditions were randomized according to an online tool (https://www.random.org/. Accessed July 3, 2018). A 5-min and a 10-min washout took place after the rest and effort conditions, respectively.

\section{Physiologic Measurements}

Breathing patterns and minute ventilation were determined by integrating flow signals with flow meters placed at the inspiratory port and at the expiratory port (Validyne: MP100 $\pm 5 \mathrm{~cm} \mathrm{H}_{2} \mathrm{O}$ ); esophageal pressure was recorded by using a simple balloon catheter connected to a differential pressure transducer (Validyne: MP45 $\pm 100 \mathrm{~cm}$ $\mathrm{H}_{2} \mathrm{O} ; \mathrm{MP} 100 \pm 100 \mathrm{~cm} \mathrm{H}_{2} \mathrm{O}$ ). Signals were digitized at $200 \mathrm{~Hz}$ and sampled by using an analogic/numeric system (Biopac MP100, Biopac Systems, Santa Barbara, California). The $\mathrm{S}_{\mathrm{pO}_{2}}$ was continuously monitored in all the subjects during the different tested conditions by using a Nonin 


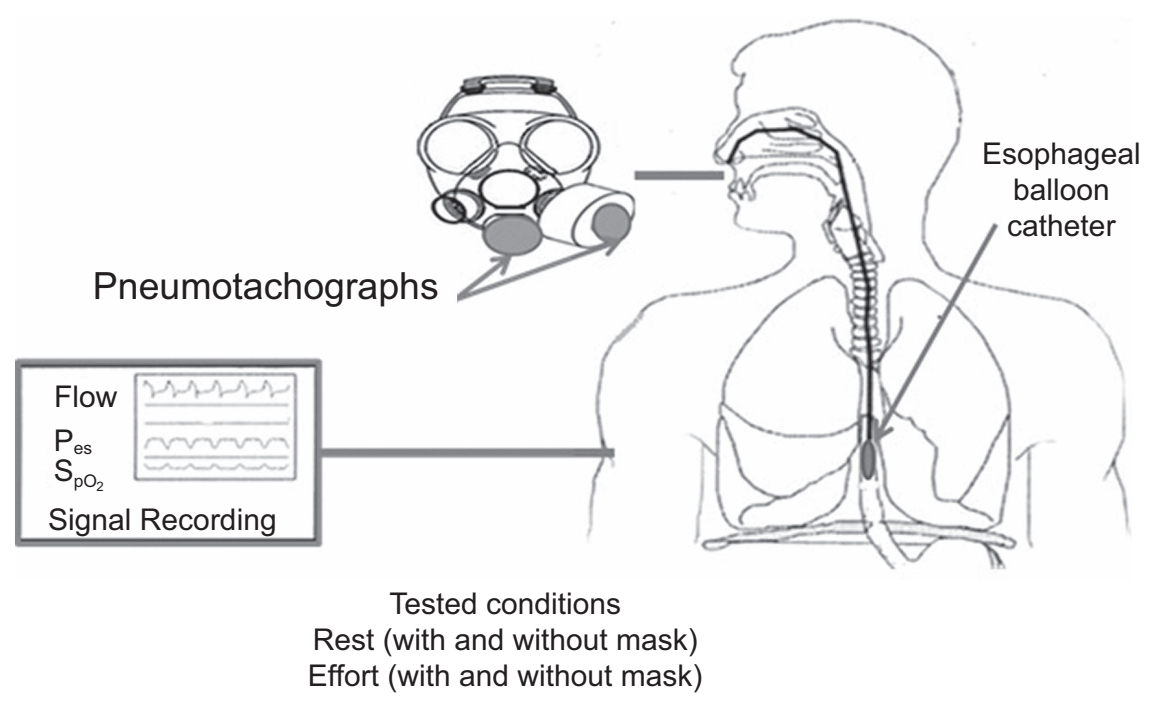

Fig. 1. Experimental setup for all tested conditions.

pulse oximeter (Nonin medical Inc., Plymouth, USA), which provided one $\mathrm{S}_{\mathrm{pO}_{2}}$ value every second. ${ }^{17}$ Capillary blood gases were collected from the fingertips right at the end of each condition, with immediate analysis in the laboratory (within a few minutes). We used capillary blood gases, which are equivalent to arterial blood gases for $\mathrm{pH}$ and $\mathrm{P}_{\mathrm{aCO}}$ analysis and do not require arterial puncture. ${ }^{18}$

\section{Data Analysis and Assessment of Subject Effort}

The subject's inspiratory WOB was calculated from esophageal pressure-tidal volume loops by using the Campbell diagram..$^{15}$ Respiratory muscle pressure-time product was calculated from the esophageal pressure signal versus inspiratory time, and esophageal pressure $\left(\right.$ Swing $\left.\mathrm{P}_{\mathrm{es}}\right)$ was recorded. Analyses were conducted with the software RESPMAT (as described by Mayaud et al ${ }^{19} 10-20$ best and stable cycles were used to compute the calculation of the WOB, as usually recommended. ${ }^{12,14,15,19,20}$ The esophageal catheter was placed as previously described. ${ }^{14}$ The Auto-PEEP and airways resistance values were also automatically calculated from RESPMAT. When evaluating the condition of the non-masked subjects, an anesthetic mask was used (3M, Brampton, Ontario, Canada). The C-4 gas mask (Airboss Defense, Bromont, Quebec, Canada) was used in masked conditions with one canister (C7A1, 3M, Ontario, Canada). The inspiratory resistance of this mask is $4.44 \mathrm{~cm} \mathrm{H}_{2} \mathrm{O}$ at $1 \mathrm{~L} / \mathrm{s}$, and the expiratory resistance is $1.25 \mathrm{~cm} \mathrm{H}_{2} \mathrm{O}$ at $1 \mathrm{~L} / \mathrm{s}$. The internal volume of the gas mask was $280 \mathrm{~mL}$, and the nose-cup volume was $80 \mathrm{~mL}$, based on a water filling technique of the different parts of the gas mask in the healthy subjects. The subjects were evaluated for their breathing pattern, index of respi- ratory effort, and capillary blood gases with and without the gas mask. To describe the variations in oxygenation during the studied conditions, we compared the difference between the mean initial $10 \mathrm{~S}_{\mathrm{pO}_{2}}$ values and the minimum $\mathrm{S}_{\mathrm{pO}_{2}}$ value.

\section{Statistical Analyses}

Statistical analyses were conducted by a biostatistician. Continuous variables were expressed as mean $\pm \mathrm{SD}$. Nominal variables were expressed as percentages. Separate statistical analyses were conducted for the groups of healthy subjects. Data were analyzed by using a 2-way mixed model. Two experimental factors, one associated with the comparison between the measurements at baseline or when hypoxemia occurred, and one associated with the comparison with or without the gas mask, factors fixed, with interaction terms between the fixed factors, were defined. These factors were analyzed as repeated measures with 2 levels by using an unstructured covariance matrix for both factors (one-on-one). For variables in which the normality assumption was not fulfilled, analyses were performed on an appropriate transformation (log and square root). A linear mixed model with repeated measurements at only one level was conducted by using an unstructured covariance matrix. The multivariate normality assumptions were verified with the Shapiro-Wilk test after a Cholesky factorization on the residuals. The results were considered significant with $P$ values of $\leq .05$. All the analyses were conducted by using the statistical package SAS, version 9.4 (SAS Institute, Cary, North Carolina) and R (Foundation for Statistical Computing, Vienna, Austria.). 
Table 1. Characteristics of the Subjects at Inclusion

\begin{tabular}{|c|c|c|c|c|c|c|c|c|c|c|}
\hline Subject no. & Sex & Age (y) & Weight $(\mathrm{kg})$ & Height $(\mathrm{cm})$ & $\mathrm{FEV}_{1}(\mathrm{~L})$ & $\mathrm{FEV}_{1}(\%)$ & FVC (L) & $\mathrm{FVC}(\%)$ & $\mathrm{FEV}_{1}: \mathrm{FVC}(\%)$ & $\mathrm{S}_{\mathrm{pO}_{2}}$ at rest $(\%)^{*}$ \\
\hline 1 & $\mathrm{M}$ & 39 & 67.8 & 170 & 4.30 & 117 & 5.96 & 134 & 72.0 & 98 \\
\hline 2 & M & 36 & 91.4 & 184 & 5.70 & 131 & 6.93 & 131 & 83.0 & 97 \\
\hline 3 & $\mathrm{M}$ & 43 & 73.2 & 179 & 4.80 & 122 & 6.39 & 132 & 94.0 & 97 \\
\hline 4 & $\mathrm{M}$ & 35 & 86.6 & 180 & 4.40 & 105 & 5.66 & 112 & 78.0 & 97 \\
\hline 5 & $\mathrm{M}$ & 31 & 88.1 & 177 & 5.50 & 130 & 6.83 & 136 & 80.0 & 98 \\
\hline 6 & $\mathrm{M}$ & 44 & 76.0 & 177 & 4.80 & 125 & 6.06 & 129 & 100 & 98 \\
\hline 7 & $\mathrm{M}$ & 36 & 75.1 & 177 & 4.50 & 114 & 5.62 & 117 & 100 & 98 \\
\hline 8 & $\mathrm{M}$ & 37 & 72.7 & 182 & 4.50 & 106 & 6.36 & 125 & 87.0 & 98 \\
\hline 9 & $\mathrm{M}$ & 51 & 74.0 & 169 & 3.00 & 93 & 3.95 & 98 & 99.0 & 98 \\
\hline 10 & $\mathrm{M}$ & 37 & 70.1 & 174 & 4.20 & 107 & 5.64 & 121 & 92.0 & 97 \\
\hline 11 & $\mathrm{M}$ & 37 & 92.4 & 173 & 3.23 & 83.6 & 4.72 & 102 & 85.1 & 94 \\
\hline 12 & $\mathrm{M}$ & 45 & 114 & 178 & 3.65 & 95.3 & 4.83 & 102 & 95.8 & 96 \\
\hline $13 \dagger$ & $\mathrm{M}$ & 31 & 68.0 & 182 & 4.86 & 110 & 6.89 & 129 & 70.6 & 98 \\
\hline 14 & $\mathrm{~F}$ & 30 & 58.3 & 160 & 3.73 & 128 & 4.67 & 139 & 85.1 & 98 \\
\hline \multirow[t]{2}{*}{15} & $\mathrm{M}$ & 37 & 91.8 & 175 & 4.05 & 103 & 4.79 & 101 & 84.5 & 97 \\
\hline & & $37.9 \pm 5.8$ & $80.0 \pm 14$ & $176 \pm 6$ & $4.35 \pm 0.8$ & $111 \pm 14$ & $5.69 \pm 0.9$ & $121 \pm 14$ & $87.0 \pm 9.6$ & $97.3 \pm 1.0$ \\
\hline $\begin{array}{l}\text { Values are prese } \\
* \text { Subject } \# 13 \mathrm{w} \\
\dagger \text { Breathing roo } \\
\mathrm{FEV}=\text { Forced } \\
\mathrm{FVC}=\text { Forced } \\
\mathrm{FEV}_{1} / \mathrm{FVC}=\mathrm{E} \\
\mathrm{S}_{\mathrm{pO}_{2}}=\text { Pulse o }\end{array}$ & $\begin{array}{l}\text { ted as } \\
\text { ss withd } \\
\text { air. } \\
\text { axpirator } \\
\text { ital Cay } \\
\text { timated } \\
\text { imetry }\end{array}$ & $\begin{array}{l}\text { lean } \pm \text { SD. } \\
\text { awn due to a vag } \\
\text { Volume } \\
\text { acity } \\
\text { ercentage value }\end{array}$ & 1 shock at the inse & tion of esophageal & atheter. & & & & & \\
\hline
\end{tabular}

\section{Results}

\section{Population}

Fifteen healthy subjects were enrolled in the study. One healthy subject was excluded from the study due to a vasovagal shock when inserting the esophageal catheter. Fourteen healthy subjects completed the clinical trial, and data were available for analysis. The age of the subjects was $37.9 \pm 5.8$ years, and they had a mean body mass index of $26.1 \pm 3.8 \mathrm{~kg} / \mathrm{m}^{2}$ and $\mathrm{a} \mathrm{FEV}_{1}$ of $4.35 \pm 0.80 \mathrm{~L}$. The sex ratio was 1:14 participants, 1 woman and 14 men, which represented the usual proportion of users for the tested devices. The characteristics of the participating healthy subjects are displayed in Table 1.

\section{Indexes of Effort}

A mean of $15.3 \pm 2.2$ stable breathing cycles were used for the analysis of the breathing pattern and the index of effort calculations. Wearing the gas mask resulted in a significant increase in all indexes of effort (Fig. 2). The WOB was significantly increased with the gas mask in comparison with the unmasked condition (rest, $3.40 \pm 1.6$ $\mathrm{J} / \mathrm{min}$ vs $4.96 \pm 3.8 \mathrm{~J} / \mathrm{min}$; effort, $76.6 \pm 46.5 \mathrm{~J} / \mathrm{min}$ vs $98.9 \pm 55.7 \mathrm{~J} / \mathrm{min} ; P=.01)$. The other respiratory indexes (WOB expressed in J/cycle, Esophageal Pressure timeProduct, and swing $\mathrm{P}_{\mathrm{es}}$ ) showed significant increases with the gas mask, at rest and with effort (Table 2). The variations in respiratory index with the gas mask at rest and during effort ranged between $30 \%$ and $60 \%$ (Fig. 3, Table 2).

\section{Breathing Pattern}

By comparing the masked with the unmasked conditions, at rest and during effort, the breathing pattern showed no significant difference in respiratory parameters (Table 3 ), whereas, in other results, these were significant. Respiratory resistances showed a significant increase with the gas mask when at rest and during effort (rest, $6.49 \pm 5.73 \mathrm{~cm}$ $\mathrm{H}_{2} \mathrm{O} / \mathrm{L} / \mathrm{s}$ vs $8.14 \pm 2.72 \mathrm{~cm} \mathrm{H}_{2} \mathrm{O} / \mathrm{L} / \mathrm{s}$; effort, $3.34 \pm 1.36 \mathrm{~cm}$ $\mathrm{H}_{2} \mathrm{O} / \mathrm{L} / \mathrm{s}$ vs $\left.6.31 \pm 2.89 \mathrm{~cm} \mathrm{H}_{2} \mathrm{O} / \mathrm{L} / \mathrm{s} ; P<.001\right)$. As for the auto-PEEP, the increases with the mask were significant (rest, $0.64 \pm 0.54 \mathrm{~L} / \mathrm{cm} \mathrm{H}_{2} \mathrm{O}$ vs $1.07 \pm 0.66 \mathrm{~L} / \mathrm{cm} \mathrm{H}_{2} \mathrm{O}$; effort, $3.08 \pm 1.64 \mathrm{~L} / \mathrm{cm} \mathrm{H}_{2} \mathrm{O}$ vs $5.71 \pm 2.39 \mathrm{~L} / \mathrm{cm} \mathrm{H}_{2} \mathrm{O} ; P<.001$ ) (Fig. 4). With the mask compared with the unmasked condition, the respiratory resistances increased by approximatively $25 \%$ at rest and $90 \%$ during effort. In the case of auto-PEEP, the increase with the gas mask was close to $70 \%$ and $90 \%$ (Fig. 4).

\section{Gas Exchange}

There was no impact on $\mathrm{pH}$ and $\mathrm{P}_{\mathrm{aCO}}$ with the gas masks (Table 4). Data for the $\mathrm{S}_{\mathrm{pO}_{2}}$ evaluation were avail- 

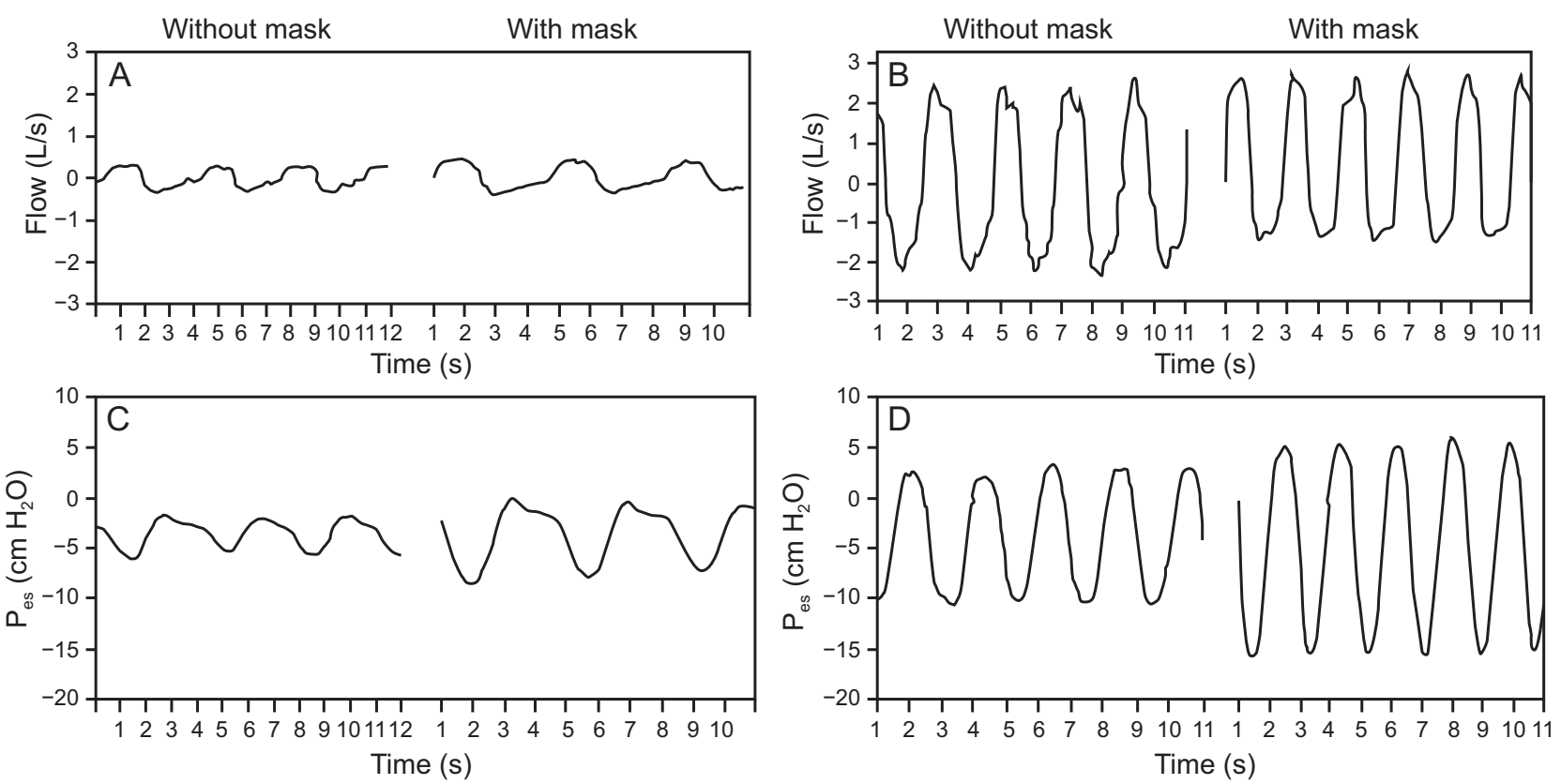

Fig. 2. Typical esophageal pressure and flow tracings at rest $(A$ and $C)$ and during effort $(B$ and $D)$, without and with a gas mask. (subject 3).

Table 2. Respiratory Index Effort at the End of the Studied Conditions

\begin{tabular}{|c|c|c|c|}
\hline Variable & WOB $(\mathrm{J} / \mathrm{cycl})$ & $\mathrm{PTP}_{\mathrm{es}}\left(\mathrm{cm} \mathrm{H} \mathrm{H}_{2} \mathrm{O} \cdot \mathrm{s} / \mathrm{min}\right)$ & Swing $\mathrm{P}_{\mathrm{es}}\left(\mathrm{cm} \mathrm{H}_{2} \mathrm{O}\right)$ \\
\hline Rest without a gas mask & $0.25 \pm 0.10$ & $109 \pm 37$ & $4.9 \pm 2.1$ \\
\hline Rest with a gas mask & $0.40 \pm 0.32 *$ & $148 \pm 67 \dagger$ & $6.5 \pm 3.0 \dagger$ \\
\hline Effort without a gas mask & $4.43 \pm 2.50$ & $461 \pm 212$ & $16.7 \pm 8.5$ \\
\hline Effort with a gas mask & $5.96 \pm 3.32 *$ & $664 \pm 271 \dagger$ & $24.2 \pm 10.5 \dagger$ \\
\hline \multicolumn{4}{|c|}{$\begin{array}{l}\text { Values are presented as mean } \pm \text { SD. } \mathrm{n}=14 . \\
* P \leq .01 . \\
\dagger P \leq .001 \\
\text { WOB }=\text { work of breathing } \\
\mathrm{PTP}_{\mathrm{es}}=\text { esophageal pressure time product } \\
\mathrm{P}_{\mathrm{es}}=\text { esophageal pressure }\end{array}$} \\
\hline
\end{tabular}

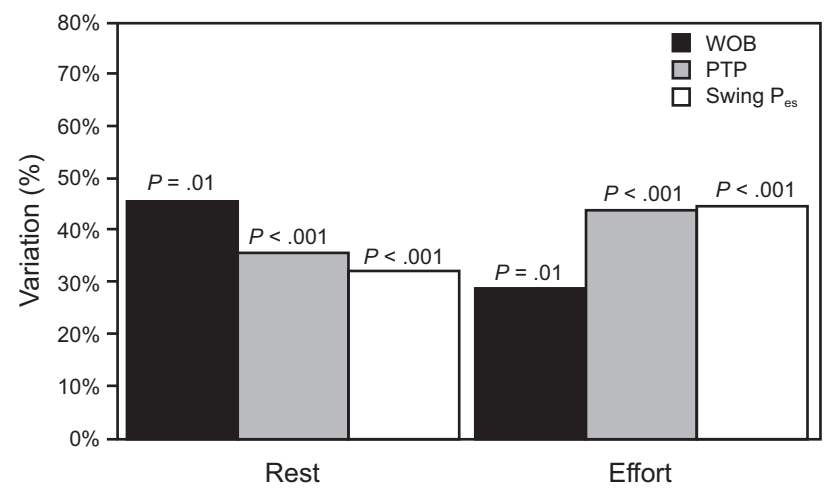

Fig. 3. Variations in the indexes of respiratory effort with the gas mask, at rest and during an effort. The $p$-values refer to the comparisons of the different indexes of effort, without and with masks. $N=14$. WOB $=$ work of breathing; PTP $=$ pressure time product; $\mathrm{P}_{\text {es }}=$ esophageal pressure. able in 12 of 14 subjects, with the available signal in $97 \%$ of the time at rest and $84 \%$ of the time during effort. The oxygenation was stable during rest with and without the gas mask but slightly decreased during effort with and without the gas mask. The mean $\mathrm{S}_{\mathrm{pO}_{2}}$ during the study conditions showed a small but significant decrease with the gas mask (rest, $96.7 \% \pm 1.0 \%$ vs $96.5 \% \pm 1.2 \%$; effort, $95.3 \% \pm 2.9 \%$ vs $94.0 \% \pm 4.1 \% ; P=.035$ ). During effort, we observed a decrease in $\mathrm{S}_{\mathrm{pO}_{2}}$ between initial values and the minimum value, which was similar with and without the gas mask $(-4.5 \% \pm 2.4 \%$ vs $-4.3 \% \pm 2.8 \%, P=.87)$. With the gas mask, 5 of 12 subjects had desaturation $>5 \% \quad \mathrm{~S}_{\mathrm{pO}_{2}}$; without the mask, such a degree of desaturation occurred in 3 subjects (Table 4). With and without the mask, the exercise induced desaturation and was persistent up to the end of 
Table 3. Breathing Pattern at the End of the Studied Conditions

\begin{tabular}{|c|c|c|c|c|c|c|c|}
\hline Variable & F (breaths/min) & $\mathrm{V}_{\mathrm{T}}(\mathrm{L})$ & $\dot{\mathrm{V}}_{\mathrm{E}}(\mathrm{L} / \mathrm{min})$ & $\mathrm{PEF}(\mathrm{L} / \mathrm{s})$ & $\mathrm{T}_{\mathrm{I}}(\mathrm{s})$ & $\mathrm{T}_{\mathrm{E}}(\mathrm{s})$ & $\mathrm{V}_{\mathrm{T}}: \mathrm{T}_{\mathrm{I}}(\mathrm{L} / \mathrm{s})$ \\
\hline Rest without a gas mask & $13.4 \pm 1.6$ & $0.50 \pm 0.11$ & $6.85 \pm 1.70$ & $0.54 \pm 0.13$ & $1.90 \pm 0.44$ & $2.64 \pm 0.40$ & $0.28 \pm 0.07$ \\
\hline Rest with a gas mask & $12.5 \pm 2.2$ & $0.57 \pm 0.21$ & $7.00 \pm 2.33$ & $0.64 \pm 0.18$ & $2.03 \pm 0.40$ & $2.93 \pm 0.77$ & $0.28 \pm 0.07$ \\
\hline Effort without a gas mask & $17.7 \pm 6.9$ & $2.25 \pm 0.78$ & $38.0 \pm 15.1$ & $2.63 \pm 0.99$ & $1.77 \pm 0.69$ & $2.10 \pm 0.78$ & $1.38 \pm 0.52$ \\
\hline Effort with a gas mask & $17.4 \pm 5.3$ & $2.22 \pm 0.63$ & $37.4 \pm 11.3$ & $2.39 \pm 0.68$ & $1.76 \pm 0.47$ & $1.97 \pm 0.57$ & $1.31 \pm 0.36$ \\
\hline $\begin{array}{l}N=14 . \\
\mathrm{F}=\text { breathing frequency } \\
\mathrm{V}_{\mathrm{T}}=\text { tidal volume } \\
\mathrm{V}_{\mathrm{E}}=\text { minute volume } \\
\mathrm{PEF}=\text { peak expiratory flow } \\
\mathrm{T}_{\mathrm{I}}=\text { inspiratory time } \\
\mathrm{T}_{\mathrm{E}}=\text { expiratory time }\end{array}$ & & & & & & & \\
\hline
\end{tabular}

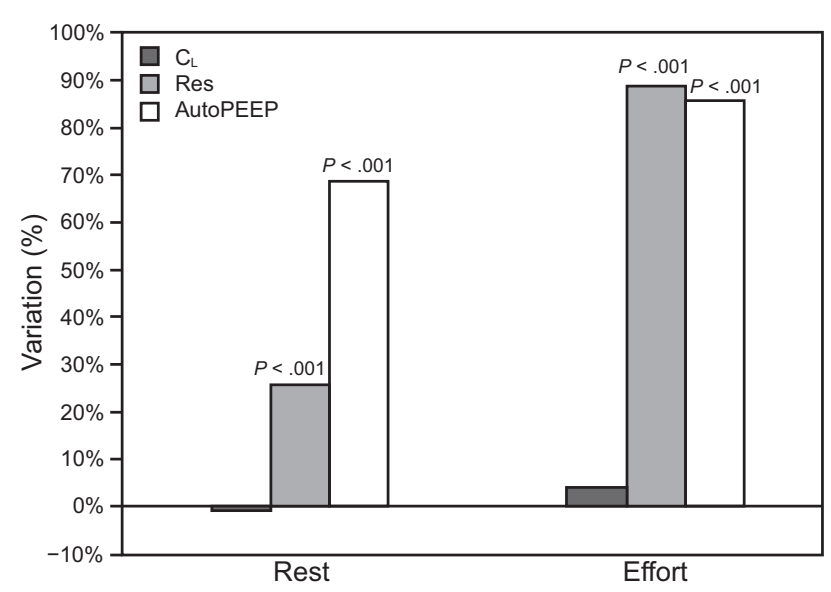

Fig. 4. Variations (\%) in the respiratory resistance and auto-PEEP with the gas mask, in comparison with and without, at rest, and during an effort. $N=14$; $C L=$ dynamic lung compliance; Res = respiratory resistance.

the exercise in 5 of 12 subjects; in other subjects, the desaturation was transient.

\section{Discussion}

To our knowledge, this was the first evaluation of a physiologic impact of the gas mask on indexes of effort, breathing patterns, and gas exchanges in human subjects. This evaluation was conducted in healthy subjects who represented the population that most frequently uses these devices (military and non-military workers). In the literature, to our knowledge, there are no data on the impact of the respiratory protection devices on the indexes of respiratory effort in human subjects. We demonstrated and quantified the increase in indexes of respiratory effort in healthy subjects. Respiratory effort indexes with a gas mask increased, up to $60 \%$, under the resting condition and up to $35 \%$ during effort. Our main hypothesis that explains this effect is (1) the impact of inspiratory and expiratory resistances due to the canister and other components of the gas mask and (2) the potential rebreathing effect within the gas mask. This effect on the WOB may explain the respiratory stress well described by users of gas masks. These data may serve as a reference to improve the design and comfort of these frequently used devices for respiratory protection.

\section{Indexes of Respiratory Effort}

The accurate measurement of the indexes of respiratory effort in healthy subjects, both at rest and during physical effort, showed the impact of the gas mask on human respiratory physiology. In all tested conditions with these subjects, at rest and during standardized effort, we demonstrated an increase in the indexes of respiratory effort with the gas mask. In the literature on gas masks, there is no study that measured the indexes of respiratory effort according to the relevant standards (ie, with the use of an esophageal balloon to measure esophageal pressure). ${ }^{12,14,15,20}$ The study by Caretti et $\mathrm{al}^{6}$ evaluated the additional WOB on a bench test but did not measure these parameters in their subjects. Their work does not represent an indirect estimation of the additional WOB, calculated on a bench to overcome several combinations of inspiratory and expiratory resistances. ${ }^{6}$ The WOB calculation in the study by Caretti et $\mathrm{al}^{6}$ was not directly measured in humans but measured on a head form and when using a breathing machine at various inspiratory and expiratory resistances. In the 11 healthy subjects included in this study, the investigators correlated a decrease in physical exercise performance with a mask along with the increase in resistance to inhalation but independent of the resistance to exhalation. ${ }^{6}$ Due to the lack of data in the literature that directly evaluated the WOB with and without a gas mask, it was not possible to make direct comparisons with our results.

The self-contained breathing apparatus is the only respirator technology for which studies have directly measured the WOB. ${ }^{21,22}$ Compared with the gas mask, self- 
Table 4. Gas Exchanges at the End of the Studied Conditions

\begin{tabular}{|c|c|c|c|c|c|}
\hline & Mean $\mathrm{S}_{\mathrm{pO}_{2}}(\%)^{*}$ & Mean Minimum $\mathrm{S}_{\mathrm{pO}_{2}}(\%)^{*}$ & $\mathrm{pH}$ & $\mathrm{P}_{\mathrm{aCO}_{2}}(\mathrm{~mm} \mathrm{Hg})$ & $\mathrm{HCO}_{3}^{-}(\mathrm{mmol} / \mathrm{L})$ \\
\hline Rest without a gas mask $\dagger$ & $96.7 \pm 1.0$ & $95.5 \pm 0.97$ & $7.40 \pm 0.02$ & $41.7 \pm 4.2$ & $25.0 \pm 0.7$ \\
\hline Rest with a gas mask $\dagger$ & $96.5 \pm 1.2 \ddagger$ & $95.4 \pm 1.07$ & $7.40 \pm 0.04$ & $41.7 \pm 4.7$ & $24.9 \pm 0.6$ \\
\hline Effort without a gas mask§ & $95.3 \pm 2.9$ & $93.5 \pm 2.5$ & $7.35 \pm 0.05$ & $43.3 \pm 6.8$ & $22.8 \pm 1.8$ \\
\hline Effort with a gas mask§ & $94.0 \pm 4.1 \ddagger$ & $92.9 \pm 2.4$ & $7.36 \pm 0.05$ & $43.6 \pm 6.3$ & $23.1 \pm 2.3$ \\
\hline \multicolumn{6}{|c|}{ 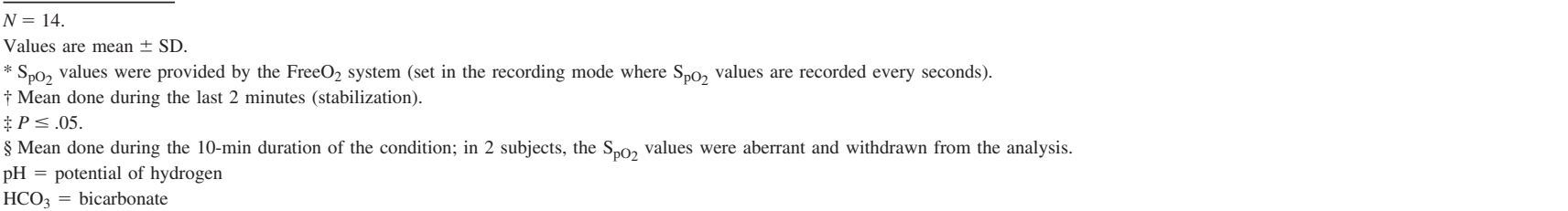 } \\
\hline
\end{tabular}

contained breathing apparatus technology works mainly with a pressurized and closed-circuit fluid supply system. Thus, we could not directly compare self-contained breathing apparatus' impact on respiratory function with gas masks due to the existence of a form of respiratory support in the self-contained breathing apparatus. The self-contained breathing apparatus is used by specialized teams of security and military forces. In the first study by Butcher et al, ${ }^{21}$ the WOB measurement was based on the self-contained breathing apparatus pressure regulator. Among 12 healthy men, the investigators adapted a methodology to the effort on a cyclometer (150-240 W) according to 2 randomized non-blind conditions. ${ }^{21}$ The first condition was when wearing the modified mask (without a pressure regulator); the second condition was with a complete mask with the pressure regulator. ${ }^{21}$ They mainly observed a 59\% increase in resistive work and an active expiration for maintaining a high minute ventilation value with the use of a pressure regulator compared with a similar condition without one. ${ }^{21}$

In 2007, the second study by Butcher et $\mathrm{al}^{22}$ evaluated the effect of the helium-oxygen mixture on respiratory parameters, fatigue of the respiratory muscles, and WOB with a self-contained breathing apparatus. In this study, the helium-oxygen mixture reduced WOB and fatigue of the respiratory muscles. Given that the gas mask and the self-contained breathing apparatus, especially with a helium-oxygen mixture, are very different technologies, a direct comparison with our data proved to be difficult. In our study, the increase in WOB and other indexes of effort may be related to increased resistances of the device (mainly the inspiratory canister) or to a rebreathing effect that led to increased respiratory drive.

\section{Impact of Resistances}

The main hypothesis that explains the increased WOB is the effect of the inspiratory resistances of the gas mask.
The resistances of the respiratory system were increased by $25 \%$ to $50 \%$ with a mask when at rest and during effort, respectively. We conducted another bench study, which evaluated resistances of the different components of the gas mask (canister, internal valves, expiratory valve). ${ }^{23}$ We demonstrated that the resistances related to the canister accounted for $80 \%$ of the inspiratory resistances and 2 of 3 of the total resistances (inspiratory and expiratory). The resistances of the canister used in the present study in healthy subjects, were $3.6 \mathrm{~cm} \mathrm{H}_{2} \mathrm{O}$ at $1 \mathrm{~L} / \mathrm{s}$ and near $10 \mathrm{~cm} \mathrm{H}_{2} \mathrm{O}$ for higher flows of $\sim 2.5 \mathrm{~L} / \mathrm{s}$, equivalent to those measured in healthy subjects during effort (Table 3). Such resistances may explain, at least in part, the increased WOB with gas masks found in this study conducted on healthy subjects. Auto-PEEP significantly increased in the subjects with a gas mask at rest $(69 \%)$ and during effort $(86 \%)$ compared with unmasked conditions. This may, in part, contribute to the increase of the WOB. Due to the tasks performance required at higher physical intensity for military personnel, security forces, and first-responders, auto-PEEP might further increase.

\section{Impact on Gas Exchange: $\mathbf{P}_{\mathrm{aCO}}$}

The impact on rebreathing related to gas-mask dead space was minor in the present study. The rebreathing within the gas mask was probably limited because $\mathrm{P}_{\mathrm{aCO}}$ was stable, without a significant increase in tidal volume, breathing frequency, and minute ventilation. In the case of rebreathing, healthy subjects are capable of increasing tidal volume or breathing frequency to increase $\mathrm{CO}_{2}$ clearance and to maintain the level of $\mathrm{P}_{\mathrm{aCO}}$. During effort, the $\mathrm{P}_{\mathrm{aCO}}$ increase with the mask was not clinically relevant, at 43.6 versus $43.3 \mathrm{~mm} \mathrm{Hg}$. These values contrasted with those of Arieli et al ${ }^{10}$ who demonstrated that wearing the gas mask in 9 healthy subjects led to hypercapnia due to the rebreathing effect. In this study, Arieli et al ${ }^{10}$ showed an increase in $\mathrm{P}_{\mathrm{aCO}_{2}}$, from 36 to $43 \mathrm{~mm} \mathrm{Hg}$ while wearing 

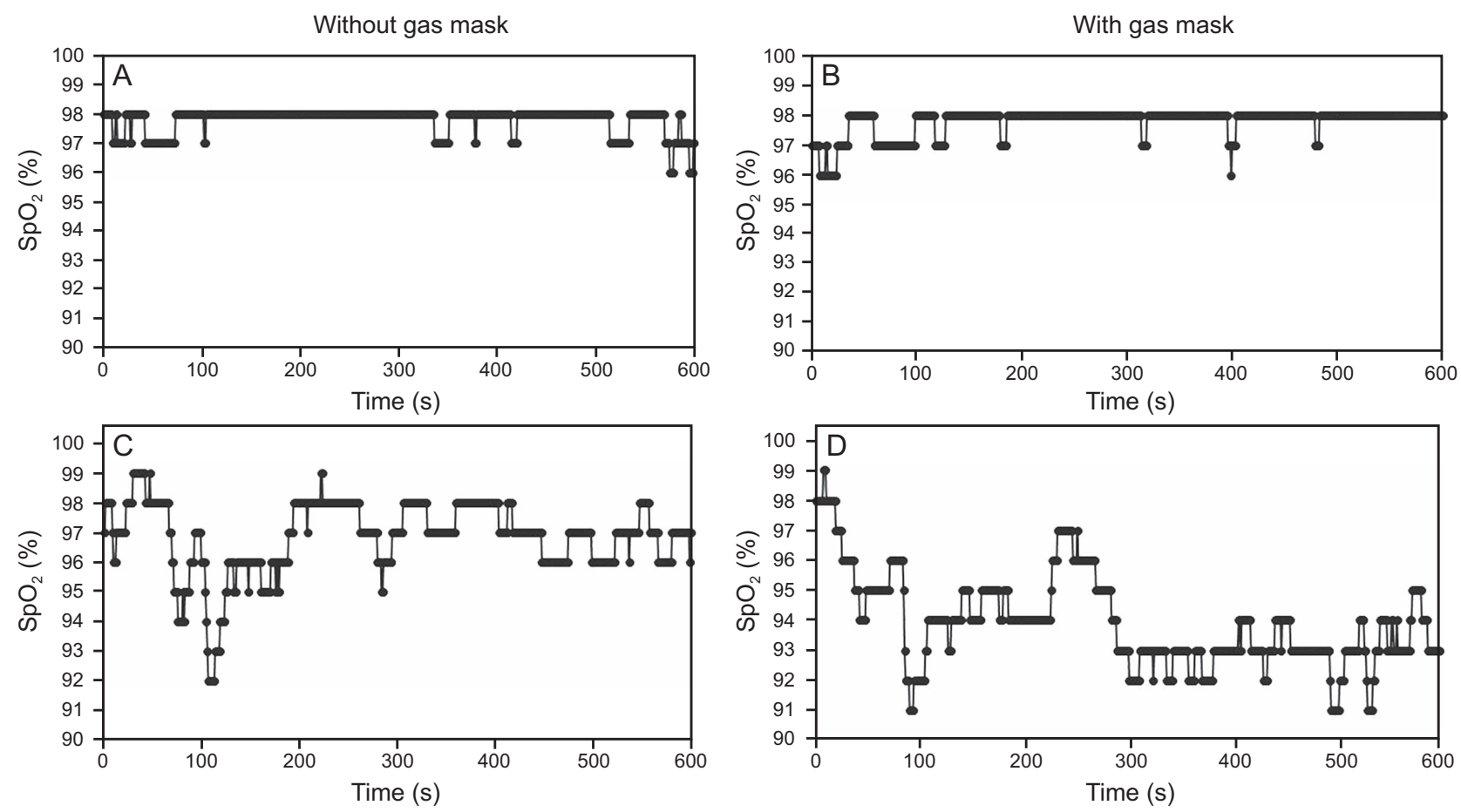

Fig. 5. Typical $\mathrm{S}_{\mathrm{pO}_{2}}$ signal tracings in the tested conditions (subject 15). A and B: During rest. C and D: During effort.

the mask for the first $5 \mathrm{~min}$ and then stabilized at $42 \mathrm{~mm} \mathrm{Hg}$ thereafter.

The level of inspired $\mathrm{CO}_{2}$ was measured in the mask, the fraction of inspired $\mathrm{CO}_{2}$ (in the internal mask-nosecup) increased to $\sim 3 \%$. The difference of internal volume of the masks probably explained the differences with our data, the total internal volume of the tested mask in the study by Arieli et $\mathrm{al}^{10}$ was $3.5 \mathrm{~L}$, and the internal volume of the internal mask (nose-cup) was $130 \mathrm{~mL}$. In our study, the mask used ( $\mathrm{C}-4$, Airboss Defense) had lower internal volumes (internal volume, $280 \mathrm{~mL}$; nose-cup, $80 \mathrm{~mL}$, according to our estimates). The investigators indicated that the mask dead spaces may explain the increase in $\mathrm{P}_{\mathrm{aCO}} \cdot{ }^{10}$ Given the complexity of our experimental setup, we did not want to add measurements of gas composition in our subjects. It, therefore, was not possible to compare our results with these data. It was possible, however, that the increase in WOB observed in our subjects was partly related to a rebreathing effect.

For all our subjects, the internal volume of the mask was $\sim 280 \mathrm{~mL}$. However, all of this volume may not be considered dead space. For all our subjects (healthy) studied at rest while using a gas mask, the WOB values were $0.40-0.67 \mathrm{~J} /$ cycle. In Fraticelli et al. ${ }^{24}$, the investigators evaluated the short-term effects of the internal volumes of several noninvasive ventilation masks, on indexes of respiratory effort, respiratory parameters, and gas exchanges. ${ }^{24} \mathrm{No}$ differences were shown in their testing up to $980 \mathrm{~mL}$ internal volume. The dead space of masks during NIV (non-invasive ventilation; and this is likely to be true with gas masks) is represented by the flow of inspiratory and expiratory gases in zones enriched in $\mathrm{CO}_{2}$, which does not constitute the totality of the internal volume of these masks. ${ }^{24}$ This concept was demonstrated by Fodil et al, ${ }^{25}$ with an analysis of gas flow distribution with different interfaces. A comparison with a $160 \mathrm{~mL}$ dead space of a C-4 gas with the data from Fratic elli et $\mathrm{al}^{24}$ cannot be directly done. Indeed, patients in this study were assessed in the acute phase of respiratory distress, with noninvasive ventilation and pressure support, whereas our subjects were healthy and without respiratory support.

\section{Impact on Gas Exchange: Oxygenation}

A significant decrease in $\mathrm{S}_{\mathrm{pO}_{2}}$ was present during effort in the mask-non-mask comparison (Fig. 5). During physical effort, for most subjects, the desaturation did not appear to be a clinical concern. In the study by Arieli et al, ${ }^{10}$ the initial $\mathrm{S}_{\mathrm{pO}_{2}}$ was $98.4 \%$ and went to $96.2 \%$ with the gas mask. The investigators found a stabilization of the $\mathrm{F}_{\mathrm{IO}_{2}}$ inside the masks at $17 \%$, again likely related to rebreathing. ${ }^{10}$ The desaturation found in the study by Arieli et al, ${ }^{10}$ was slightly less than in our study. However, the desaturation described in the study by Arieli et al, ${ }^{10}$ was found at rest, and no evaluation during effort was conducted. In our study, the desaturation at rest was not clinically relevant (less than in the study by Arieli et $\mathrm{al}^{10}$ ), but there was a significant exercise-induced hypoxia, $>5 \%$ desaturation in several subjects. However, the masks did not have a sig- 
nificant impact on this effect. Exercise-induced desaturation is well described and usually moderate. ${ }^{10,26-30}$ However, we found that wearing a gas mask during exercise did not increase this effect.

Finally, our hypothesis was that the increase in WOB with gas masks seems to mainly be related to increased inspiratory resistances with a possible minor effect of rebreathing that we could not completely rule out. Our hypothesis is that the part related to the dead space of the mask is limited and that the impact of the resistances is predominant to explain indexes of respiratory effort and the respiratory stress with these masks. To definitively come to a conclusion about rebreathing, it would be better to analyze the gas flow at the inhalation and exhalation inside the mask and, in particular, in the nose-cup.

\section{Study Limitations}

We have not fully evaluated the technological dead space of gas masks. In fact, as discussed above the internal volume did not correspond directly to the dead space of these devices. Nevertheless, we could not measure the exact internal volume of the masks, the inspired and exhaled fractions of $\mathrm{O}_{2}$ and $\mathrm{CO}_{2}$ from the gases within the mask, or the respiratory flow pattern traveling within the mask. As a result, we could not assess the exact amount of dead space with these devices. Therefore, we could not provide a definitive conclusion on the issue of the rebreathing role in indicies of increased effort. There were a limited number of subjects included in the study. However, all the subjects showed similar changes in evaluated parameters, especially on indexes of effort. We are confident that the data were generalizable to most gas mask users. AutoPEEP might have been slightly overestimated because it was measured with an esophageal balloon and without the gastric pressure correction. ${ }^{31}$ Also, the study was not blinded, but this was not feasible within this specific topic.

\section{Conclusions}

Our data accurately depicts the impact of gas masks on healthy subjects at rest and during effort. We demonstrated a clear increase of indexes of effort, without a relevant impact on respiratory patterns or gas exchanges. These effects were observed both at rest and during effort. There are several potential explanations to the increased indexes of effort with masks, mainly increased resistances, rebreathing, and increased auto-PEEP. The exact contribution of each component could not be determined from our data. The analysis of the results indicated that the increases of the indexes of effort were more related to the increase of the gas-mask resistances, although there may be a rebreathing effect due to the dead space of the gas mask. This did not seem to have been significant in the tested conditions. Nevertheless, our data did not allow us to make a definitive conclusion on this point.

Because it is one of the main entry routes for the chemical, biologic, radiologic, nuclear, and explosive agents, respiratory system protection must be achieved through the use of gas masks. A better tolerance of these devices by minimizing respiratory stress will improve the performance of the users and allow wider use, even in those with respiratory conditions. Our results were limited to the gas masks used in this study but may be extended to similar masks. Also, in our measurements, the control subjects breathed through anesthetic masks to do a proper comparison with the gas mask.

\section{ACKNOWLEDGMENTS}

We thank Serge Simard MSc, for his biostatistical analysis, Marc Dauphin MD, for his military medicine mentorship, Kathrine Barrett MA, for her feedback in the use of the English language, and Eva Dickson PhD, for scientific collaboration and her shared expertise in chemical, biologic, radiologic, nuclear, and explosive agents.

\section{REFERENCES}

1. Central Intelligence Agency Library, The World Factbook, https://www. cia.gov/library/publications/the-world-factbook/geos/us.html. Accessed December 15, 2017.

2. Hiss JA, Arensburg B. Suffocation from misuse of gas masks during the Gulf war. BMJ 1992;304(6819):92.

3. Jetté M, Thoden J, Livingstone S. Physiological effects of inspiratory resistance on progressive aerobic work. Eur J Applied Physiol Occup Physiol 1990;60(1):65-70.

4. Johnson AT, Cummings EG. Mask design considerations. Am Ind Hyg Assoc J 1975;36(3):220-228.

5. Silverman L, Lee RC, Lee G, Drinker KR, Carpenter TM. Fundamental factors in the design of protective respiratory equipmentInspiratory air flow measurements on human subjects with and without resistance. Department of Physiology and of Industrial Hygiene, Harvard School of Public Health, and the Nutrition Laboratory of the Carnegie Institution of Washington. Boston, MA: Harvard Press; 1951.

6. Caretti DM, Coyne K, Johnson A, Scott W, Koh F. Performance when breathing through different respirator inhalation and exhalation resistances during hard work. J Occup Environ Hyg 2006;3(4):214224; quiz D245.

7. Caretti DM, Scott WH, Johnson AT, Coyne KM, Koh F. Work performance when breathing through different respirator exhalation resistances. AIHAJ 2001;62(4):411-415.

8. Johnson AT, Scott WH, Lausted CG, Coyne KM, Sahota MS, Johnson MM. Effect of external dead volume on performance while wearing a respirator. AIHAJ 2000;61(5):678-684.

9. Smith G, Bishop P, Beaird J, Ray P, Smith J. Physiological factors limiting work tolerance in chemical protective clothing. Int J Industrial Ergonomics 1994;13:147-155.

10. Arieli R, Arieli Y, Eynan M, Abramovich A. Use of a fast transcutaneous CO2 detector to evaluate escape hoods: the "CAPS 2000" with the inlet valves removed from the nose-cup as a test case. Mil Med 2012;177(11):1426-1430.

11. Johnson AT, Scott WH, Lausted CG, Benjamin MB, Coyne KM, Sahota MS, Johnson MM. Effect of respirator inspiratory resistance level on constant load treadmill work performance. Am Ind Hyg Assoc J 1999;60(4):474-479. 


\section{Impact of Gas Masks on Ventilation Variables}

12. Baydur A, Behrakis PK, Zin WA, Jaeger M, Milic-Emili J. A simple method for assessing the validity of the eosophageal balloon technique. Am Rev Respir Dis 1982;126(5):788-791.

13. Bellani G, Pesenti A. Assessing effort and work of breathing. Curr Opin Crit Care 2014;20(3):352-358.

14. Milic-Emili J, Mead J, Turner J. Topography of esophageal pressure as a function of posture in man. J Appl Physiol 1964;19:212-216.

15. Tobin JM. Principles and Practice of Intensive Care Monitoring. McGraw-Hill: 1998;1525.

16. Jetté M, Sidney K, Blümchen G. Metabolic equivalents (METS) in exercise testing, exercise prescription, and evaluation of functional capacity. Clin Cardiol 1990;13(8):555-565.

17. Lellouche F, L'her E. Automated oxygen flow titration to maintain constant oxygenation. Respir Care 2012;57(8):1254-1262.

18. Zavorsky GS, Cao J, Mayo NE, Gabbay R, Murias JM. Arterial versus capillary blood gases: a meta-analysis. Respir Physiol Neurobiol 2007;155(3):268-279.

19. Mayaud L, Lejaille M, Prigent H, Louis B, Fauroux B, Lofaso F. An open-source software for automatic calculation of respiratory parameters based on esophageal pressure. Respir Physiol Neurobiol 2014; 192:1-6.

20. Cabello B, Mancebo J. Work of breathing. Intensive Care Med 2006; 32(9):1311-1314.

21. Butcher SJ, Jones RL, Eves ND, Petersen SR. Work of breathing is increased during exercise with the self-contained breathing apparatus regulator. Appl Physiol Nutr Metab 2006;31(6):693-701.

22. Butcher SJ, Jones RL, Mayne JR, Hartley TC, Petersen SR. Impaired exercise ventilatory mechanics with the self-contained breathing apparatus are improved with heliox. Eur J Appl Physiol 2007;101(6): 659-669.

23. Bourassa S, Lellouche F. Measurement of pressure-flow relationship for the gas mask technology on a bench test. Partitioning of the different components of the mask and comparison of 8 canisters [Abstract]. CIMVHR Forum; 2017;8(suppl):P126.

24. Fraticelli AT, Lellouche F, L'her E, Taillé S, Mancebo J, Brochard L. Physiological effects of different interfaces during noninvasive ventilation for acute respiratory failure. Crit Care Med 2009;37(3): 939-945.

25. Fodil R, Lellouche F, Mancebo J, Sbirlea-Apiou G, Isabey D, Brochard $\mathrm{L}$, et al. Comparison of patient-ventilator interfaces; based on their computerized effective dead; space. Intensive Care Med 2010;37(2): 193-195.

26. Anchisi S, Moia C, Ferretti G. Oxygen delivery and oxygen return in humans exercising in acute normobaric hypoxia. Pflugers Arch 2001; 442(3):443-450.

27. Dempsey JA, Wagner PD. Exercise-induced arterial hypoxemia. J Appl Physiol 1999;87(6):1997-2006.

28. Dominelli PB, Foster GE, Dominelli GS, Henderson WR, Koehle MS, McKenzie DC, Sheel AW. Exercise-induced arterial hypoxaemia and the mechanics of breathing in healthy young women. J Physiol 2013;591(12):3017-3034.

29. Romer LM, Haverkamp HC, Lovering AT, Pegelow DF, Dempsey JA. Effect of exercise-induced arterial hypoxemia on quadriceps muscle fatigue in healthy humans. Am J Physiol Regul Integr Comp Physiol 2006;290(2):R365-375.

30. Walls J, Maskrey M, Wood-Baker R, Stedman W. Exercise-induced oxyhaemoglobin desaturation, ventilatory limitation and lung diffusing capacity in women during and after exercise. Eur J Appl Physiol 2002;87(2):145-152.

31. Lessard MR, Lofaso F, Brochard L. Expiratory muscle activity increases intrinsic positive end-expiratory pressure independently of dynamic hyperinflation in mechanically ventilated patients. Am J Respir Crit Care Med 1995;151(2 Pt 1):562-569.

This article is approved for Continuing Respiratory Care Education credit. For information and to obtain your CRCE

(free to AARC members) visit www.rcjournal.com

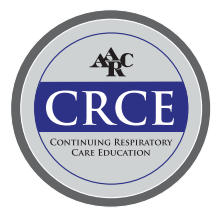

